$q$

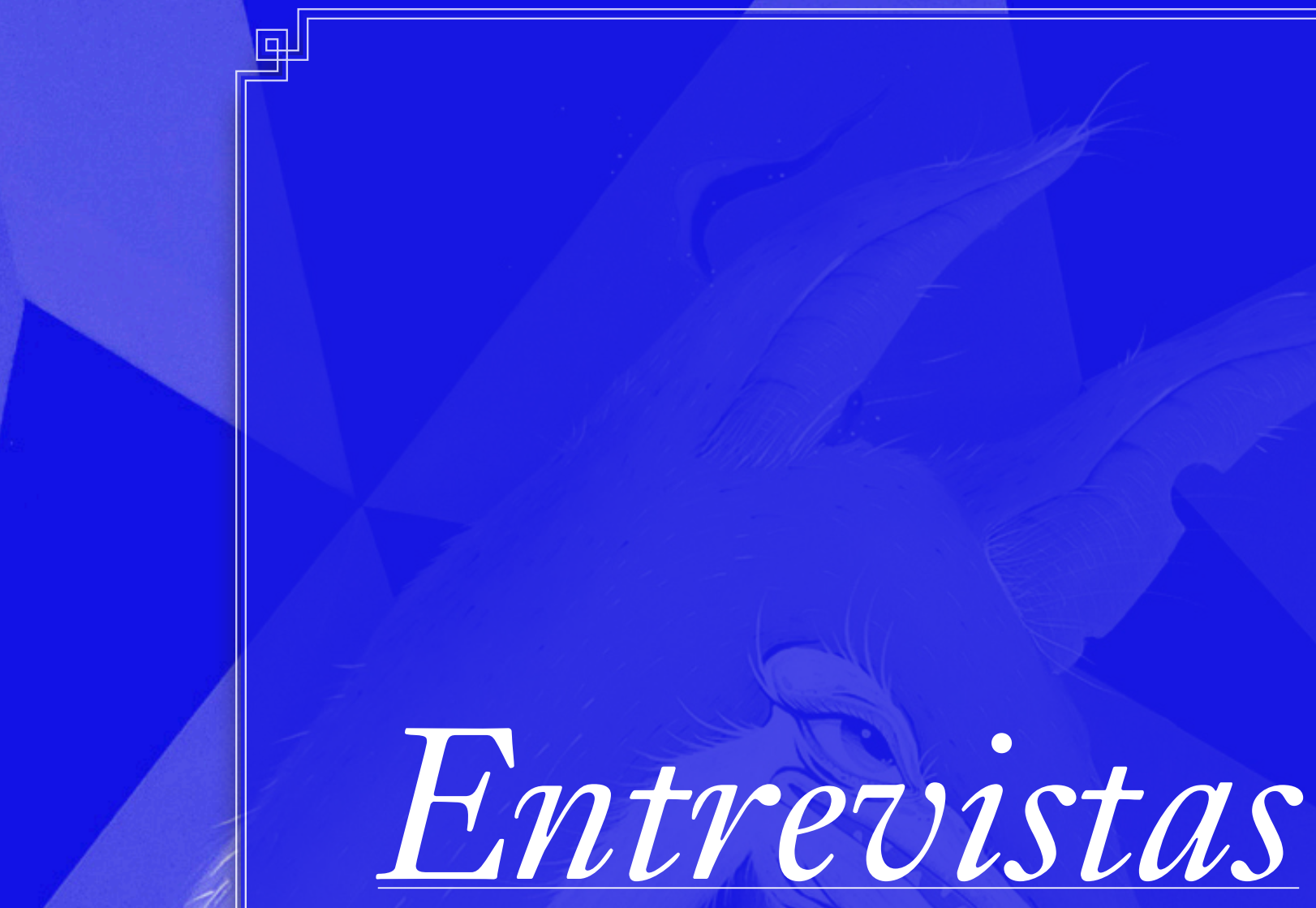

回 


\section{Jorge Araújo: \\ literatura, história e política}

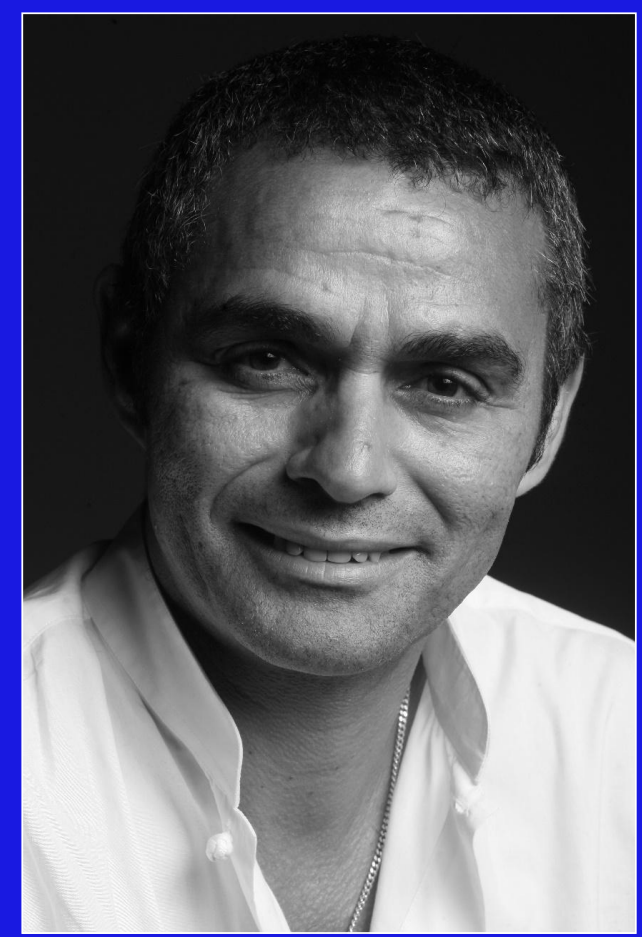

Avani Souza Silva

FOTO POR JORGE SIMÃO

1 Graduada em Letras pela Universidade de São Paulo, Mestre e doutora pelo Programa de Pós-Graduação em Estudos Comparados de Literaturas de Língua Portuguesa da mesma instituição. Especialista em Língua Portuguesa pela Pontifícia Universidade Católica de São Paulo. Membro do Grupo de Pesquisa Produções Literárias e Culturais para Crianças e Jovens (CNPq/USP). 
Agora és o homem da casa - determinou Abdelei, com as palavras vestidas de pólvora.

O futuro é como um relâmpago.

Beija-mim

Os olhos eram lâmpadas de medo.

Cinco balas contra a América

Jorge Araújo nasceu em 1959, na cidade do Mindelo, capital da Ilha de São Vicente, no Arquipélago de Cabo Verde. Passou a infância e adolescência nessa cidade, até hoje considerada a capital cultural do Arquipélago, e berço da Claridade - revista de arte e letras, criada em 1936, importante veículo de emancipação e de publicação literária e cultural dos intelectuais cabo-verdianos.

Após terminar o Liceu, mudou-se para a Bélgica onde se licenciou em Comunicação Social e Teatro. Iniciou sua carreira jornalística na TV em Cabo Verde, tendo uma passagem rápida pela diplomacia, mas é com reportagens que se realiza. Trabalhou para $O$ Independente, para o fá, para TVI, para a BBC de Londres, dirigiu a revista "Domingo", do Correio da Manhã, e atualmente é editor da Revista do Semanário Expresso. Como jornalista, venceu o Grande Prêmio Gazeta (1999) e o Prêmio AMI - Jornalismo Contra a Indiferença, em 2002. Como escritor, venceu o Prêmio Gulbenkian, pela qualidade literária, com o livro Comandante Hussi (2003), traduzido para o espanhol em 2007.

Detentor de um olhar arguto, o escritor desvela com sensibilidade os mais íntimos conflitos humanos. Questões identitárias, históricas e políticas perpassam a arquitetura narrativa. Construtor de uma linguagem simbólica leve e precisa, sem esquecer a ironia e o humor, resgata a oralidade, utilizando elementos discursivos detidamente elaborados em um fazer poético engenhoso, estabelecendo múltiplos diálogos interculturais. Sua narrativa é densa e fluida ao mesmo tempo. O olhar para a infância, como escritor e jornalista, é dos mais comoventes.

Publicou Timor, o insuportável ruído das lágrimas (2000), Comandante Hussi (2003), Nem tudo começa com um beijo (2005), Paralelo 75 ou o segredo de um coração traído (2006), Cinco balas contra a América (2007). Essas quatro últimas ilustradas pelo angolano Pedro Sousa Pereira, 
jornalista da estação de televisão SIC, que o escritor conheceu em plena reportagem no Timor-Leste durante o massacre de 1999. Seguiram-se: O dia em que a noite se perdeu (2008), Beija-Mim (2010) e O cemitério dos amores vivos (2015), seu último romance.

Abaixo a entrevista, gentilmente concedida por e-mail, em que ele discorre sobre seu processo criativo, mostrando a aproximação entre jornalismo e literatura.

I. A tua reportagem ampliada, como você nomeia o diário "A noite protege os cobardes", faz parte do seu livro Timor: o insuportável ruído das lágrimas, organizado por você e escrito por mais três colegas jornalistas que estiveram no Timor-Leste por ocasião do massacre de I999. Essa tua narrativa, aliando História e recursos literários, permeada por uma linguagem simbólica, desde o prólogo do livro, imprime tom dinâmico, denso e dramático à sucessão dos acontecimentos narrados, do horror, da evacuação dos jornalistas estrangeiros, e prova suspense no leitor. Você considera essa a sua primeira experiência literária ou o embrião do jornalismo literário?

Gosto de contar histórias e acredito que as reportagens para cativarem o leitor têm de ser vividas. Pode-se contar a realidade com recurso a técnicas próprias da literatura. O jornalismo literário é uma escola com bastantes anos e seguidores. É, desde os primeiros passos no jornalismo, a minha casa. Este livro nasce no seguimento de um trabalho jornalístico, de uma longa presença no terreno. Trata-se de jornalismo, jornalismo literário, se assim quiser catalogar.

2. Você incentiva a prática do jornalismo literário na Revista do Semanário Expresso, da qual você é o editor? Como?

A revista é conhecida pelas suas reportagens e pelo cuidado na forma de contar as histórias. Tento ter jornalismo literário, mas este estilo não só, por requerer muito tempo como também um domínio diferente da escrita. Além disso, não é natural à maioria dos jornalistas. 
3. Como você foi mobilizado internamente para escrever a matéria sobre o golpe militar na Guiné-Bissau, em I999, em que você conheceu o menino Hussi? Como a matéria resultou no livro Comandante Hussi?

Fui destacado para a Guiné-Bissau logo após o golpe de Estado que destituiu o antigo Presidente Nino Vieira porque era o jornalista mais habituado a cenários de conflito. Entre outros, estivera já em Angola, Moçambique, Bósnia e na África do Sul durante o dramático apartheid. Em relação ao Hussi, ouvi a história pela primeira vez da boca do próprio pai, então soldado das forças rebeldes. Achei a história do menino-soldado tão tocante que decidi seguir-lhe o rasto. Acabei assim por conhecer o Hussi.

4. A bicicleta é um sonho de consumo das crianças, muitas vezes interdito, e traz consigo a ideia de liberdade e locomoção... Essa simbologia é encontrada em diversas obras literárias. Penso em O Comandante Hussi, mas também no livro $A$ bicicleta que tinha bigodes (201 I), do escritor angolano Ondjaki, e até no conto “O enterro da bicicleta” (2007), do moçambicano Nelson Saúte. Seria a bicicleta a metáfora da infância nos países africanos de língua portuguesa?

Mais do que a metáfora da infância, é a metáfora da liberdade. Da independência. 
5. Sua obra, tanto especificamente do gênero infantil e juvenil (Comandante Hussi, Cinco balas contra a América, Beija-mim) bem como os romances escritos para adultos (em que alguns têm ressonância no público juvenil, como é o caso de Nem tudo começa por um beijo), revisita os países de língua portuguesa (Portugal, Cabo Verde, Guiné-Bissau, Angola). Eles aparecem não só como elementos estruturais da narrativa, mas também envolvendo questões sociais específicas, como é o caso dos retornados em Paralelo 75 ou O segredo de um coração traído. Como você entende essa diversidade de espaço narrativo: uma denúncia das mazelas do colonialismo/neocolonialismo, uma homenagem aos povos desses países, ou ambas as coisas?

Talvez seja tudo isso e mais um pouco. É uma realidade que conheço bem, que me alimenta a memória. Na verdade, é a minha realidade. Nasci em Cabo Verde, cresci com o colonialismo e experimentei a independência na adolescência. Dos instantes decisivos, ninguém escapa ileso.

6. Outro aspecto singular de suas obras é a linguagem simbólica marcada por deslocamentos semânticos, neologismos, rimas e assonâncias. De que forma você forjou essa linguagem? Quais foram os autores que leu?

O estilo de cada autor vai-se construindo, faz-se fruto do que lê, mas acima de tudo de quem é. De onde vem, de quem ouviu. A linguagem é a soma de todas essas influências e do compasso com que sente a história e com que se encara a própria vida. Escrevo como sinto, como ouvi o meu pai e o meu padrinho narrarem aventuras. É uma escrita fundeada na oralidade. 
7. O livro Comandante Hussi, premiado por sua qualidade literária pela Fundação Gulbenkian, foi o primeiro livro da literatura infantil e juvenil cabo-verdiana publicado no Brasil, gerando diversos trabalhos acadêmicos sobre ele. Por que a obra nunca foi publicada em Cabo Verde?

Creio que essa pergunta deve ser colocada aos editores de Cabo Verde. Mas também é verdade que nunca contatei nenhum.

8. Como você vê a atual literatura cabo-verdiana produzida no Arquipélago depois de dois prêmios Camões: para o poeta e ensaísta Arménio Vieira, em 2009, e para o escritor Germano Almeida, em 2018?

Esses prémios são importantes, dão visibilidade à literatura cabo-verdiana. Mas, confesso, continuo a gostar mais dos autores do movimento Claridade como Baltasar Lopes da Silva, Jorge Barbosa, Manuel Lopes e Teixeira de Sousa.

9. A sua escrita é essencialmente novelística ou romanesca, você já pensou em escrever narrativas mais breves, como os contos?

Tenho um livro de contos escrito. Respira na gaveta há mais de um ano. Ao longo de 36 dias, escrevi 36 contos. Talvez um dia se façam livro. Talvez não. Gosto cada vez mais da gaveta. 